\title{
Sudden deafness in a patient with secondary syphilis and HIV infection
}

\author{
Mădălina Gabriela Georgescu ${ }^{1,2^{*}}$, Daniela Anghel ${ }^{2,3}$, Dana Mihai ${ }^{4}$ \\ From The 9th Edition of the Scientific Days of the National Institute for Infectious Diseases Prof Dr Matei Bals \\ Bucharest, Romania. 23-25 October 2013
}

\section{Background}

We emphasize the importance of considering a diagnosis of early acquired syphilis in sexually active adults, and review the ENT manifestations and treatment of acquired syphilis.

\section{Case report}

A 41-year-old man with left side hearing impairment since childhood presented with sudden hearing loss in the right ear; mild imbalance and clinical features suggestive of secondary syphilis (skin rash) developed lately. The first choice of treatment in the ENT department was followed after initial favorable evolution by relapsed sudden hearing loss in the right ear, dizziness, vertigo, nausea, and vomiting and gait impairment. The correct diagnosis was made after multiple evaluations in ENT, neurology, dermatology and infectious diseases departments.

Combined ENT and infectious diseases treatment resulted in only partial recovery of hearing in the right ear and complete absence of dizziness.

\section{Conclusion}

With the exponential rise in syphilis cases in Romania, there has been a reemergence of presenting manifestations that had previously become rare. Early syphilis should be considered in all sexually active adults who present with deafness, as prompt diagnosis and treatment are crucial for maximum recovery.

\section{Authors' details}

'Institute of Phono-Audiology and ENT Functional Surgery, Bucharest, Romania. ${ }^{2}$ Carol Davila University of Medicine and Pharmacy,

Bucharest, Romania. ${ }^{3}$ Department of Neurology, Fundeni Clinical Institute,

\footnotetext{
* Correspondence: madalina.georgescu@gecad.com

${ }^{1}$ Institute of Phono-Audiology and ENT Functional Surgery, Bucharest, Romania

Full list of author information is available at the end of the article
}

Bucharest, Romania. ${ }^{4}$ Department of Dermatology, Fundeni Clinical Institute, Bucharest, Romania.

Published: 16 December 2013

doi:10.1186/1471-2334-13-S1-P15

Cite this article as: Georgescu et al:: Sudden deafness in a patient with secondary syphilis and HIV infection. BMC Infectious Diseases 2013 13(Suppl 1):P15.
Submit your next manuscript to BioMed Central and take full advantage of:

- Convenient online submission

- Thorough peer review

- No space constraints or color figure charges

- Immediate publication on acceptance

- Inclusion in PubMed, CAS, Scopus and Google Scholar

- Research which is freely available for redistribution

Submit your manuscript at www.biomedcentral.com/submit
( Biomed Central

\section{Biomed Central}

